\title{
Analysis of microbial populations in plastic-soil systems after exposure to high poly(butylene succinate-co-adipate) load using high-resolution molecular technique
}

\author{
Benjawan Tanunchai ${ }^{1}$ (1), Kantida Juncheed ${ }^{2}$, Sara Fareed Mohamed Wahdan 1,3,4, Vusal Guliyev, ${ }^{1,5}$, \\ Maria Udovenko ${ }^{1}$, Ann-Sophie Lehnert ${ }^{6}$, Eliane Gomes Alves ${ }^{6}$, Bruno Glaser ${ }^{7}$, Matthias Noll ${ }^{8}$, \\ François Buscot $\cot ^{1,9+} \mathbb{B}$, Evgenia Blagodatskaya ${ }^{1,10+}$ and Witoon Purahong ${ }^{1 *+} \bullet$
}

\begin{abstract}
Background: Bio-based and biodegradable plastics are considered as plastics of the future owing to their ability to decompose under various environmental conditions. However, their effects on the soil microbiome are poorly characterised. In this study, we aimed to investigate the effects of an important bio-based and biodegradable plastic, polybutylene succinate-co-adipate (PBSA), on soil microbial diversity and community composition using high-resolution molecular technique (Illumina sequencing) targeting all three microbial domains: archaea, bacteria, and fungi.

Results: Adding high load of PBSA to soil $(6 \%(\mathrm{~W} / \mathrm{W}))$ caused a significant decline in archaeal (13\%) and fungal (45\%) richness and substantial changes in both bacterial (Proteobacteria, Actinobacteria, and Acidobacteria) and fungal (Eurotiomycetes, Sordariomycetes, Leotiomycetes, and Dothideomycetes) community composition compared with no PBSA addition to soil. The combined effects of PBSA and $\left(\mathrm{NH}_{4}\right)_{2} \mathrm{SO}_{4}$ fertilisation on the soil microbiome were much greater than the effects of PBSA alone. We only detected opportunistic human pathogens in low abundance on PBSA and in the surrounding soil. However, some plant pathogenic fungi were detected and/or enriched on the PBSA films and in surrounding soil. Apart from plant pathogens, many potential microbial control agents and plant growthpromoting microorganisms were also detected/enriched owing to PBSA addition. Adding high load of PBSA together with $\left(\mathrm{NH}_{4}\right)_{2} \mathrm{SO}_{4}$ fertilisation can either eliminate some plant pathogens or enrich specific pathogens, especially Fusarium solani, which is economically important.
\end{abstract}

Conclusions: We conclude that high load of bio-based and biodegradable PBSA plastic may negatively affect soil microbiome.

Keywords: PBSA, Metabarcoding, Plant health, Human health, Plant growth-promoting microbes, N-fixing bacteria, Biological control agents, Plant pathogens

*Correspondence: witoon.purahong@ufz.de

${ }^{\dagger}$ François Buscot, Evgenia Blagodatskaya, Witoon Purahong are senior authors

1 Department of Soil Ecology, UFZ-Helmholtz Centre for Environmental Research, Theodor-Lieser-Str. 4, 06120 Halle (Saale), Germany Full list of author information is available at the end of the article

\section{Background}

Biodegradable plastics can be produced by both biobased and petroleum-based raw materials [1]. Biodegradability of plastics is not directly linked to the origin of raw materials. On the one hand, many bio-based plastics (e.g. lignin-based plastics, bio-polyethylene, bio-polyethylene terephthalate) have only limit biodegradability and 
some of them are classified as non-biodegradable $[2,3]$. On the other hand, some petroleum-based plastics are biodegradable [1]. Nowadays, many petroleum-based and biodegradable plastics (including, polybutylene succinate (PBS) and polybutylene succinate-co-adipate (PBSA)) [1] can be produced by bio-based raw materials and considered as bio-based and biodegradable plastics. Bio-based and biodegradable plastics are considered as eco-friendly plastics because they decompose under various environmental conditions and are less toxic to ecosystems [4]. Moreover, their production not only reduces the use of non-renewable resources, particularly fossil fuels, but also the emission of greenhouse gases, which are the main drivers of anthropogenic climate change, compared with petroleum-based plastics [5]. Because of the negative effects of petrochemical plastics on environmentally sensitive marine and terrestrial ecosystems, the European Union issued a law banning single-use plastics by 2021 and introduced taxes on other countries, such as China, India, and the United Kingdom [5]. Owing to these constraints, the demand for biodegradable plastics has increased globally [4]. Currently, polylactic acid (PLA), PBS, and its derivatives, i.e. PBSA, polyhydroxyalkanoate (PHA), and polybutylene adipate terephthalate (PBAT), are commercially available bio-based and biodegradable plastics that lead in market share [4]. However, PLA should be considered as bio-based and compostable plastic because it requires a high temperature during composting to be degraded due to its high glass transition temperature $\left(60^{\circ} \mathrm{C}\right)$ [6]. The concentration of microbes is also a factor that accelerates the degradation of PLA [6, 7]. By contrast, PBS, PBSA, PHA, and PBAT are degraded in soils at ambient or lower temperature [8]. Among them, PBS and PBSA are promising materials and commercially available [9]. PBS and its composites have mechanical and physical properties, which closely resemble those of conventional plastics, such as polyethylene (PE) and polypropylene (PP) [9-11]. The mechanical flexibility of PBS can also be improved by blending with other bioplastics [11]. They are commercially used in agriculture, fishery, food packaging, durable construction, and medicine [11]. For instance, PBS and PBSA are among the commonly used biodegradable mulch films in agricultural fields to preserve moisture in agricultural soil and regulate soil temperature [12]. They are also used as carriers for drug delivery and in medical materials for drug encapsulation systems [13].

Currently, almost all plastics widely used in various sectors have been intentionally and unintentionally disposed of in both terrestrial and aquatic ecosystems [14, 15]. Excessive usage of food packaging is responsible for $40 \%$ of plastic waste globally $[7,16]$, while plastic mulching film is the major source of plastic pollution in terrestrial soil ecosystems $[17,18]$. Food packaging plastics are unintentionally released into terrestrial soils, are transported by rivers, and end up as important sources of plastic pollution to oceans $[19,20]$. In agriculture, after harvesting, plastic residues may be left in the field despite removal efforts. In some cases, farmers may leave residues on their fields and till them into soil $[14,18]$. Moreover, during degradation, PBS and PBSA can release $\mathrm{CO}_{2}, \mathrm{H}_{2} \mathrm{O}$, monomers (e.g. succinic acid, 1,4-butanediol, and adipic acid), and lowmolecular mass oligomers, which are water-soluble [21]. Monomers, such as succinic acid and 1,4-butanediol, can be used by soil microbes in the tricarboxylic acid or Krebs cycle as precursors to produce cellular energy [22]. During its decomposition period, PBSA remains present in soils for at least one year under natural conditions; thus, it can interact with soil microbes and the environment $[8,23]$. Plastic residues in soils may host microorganisms, including various pathogens and beneficial microbes [1,24], thus colonisation of plastics by pathogens can elevate disease risks as the pathogens are facultative decomposers which can use plastic residues to grow and reproduce. However, only few observations of beneficial microbes associated with PBS, PBSA, and other bio-based and biodegradable plastics are reported [12, 24, 25]. Although previous studies have shown that the decomposition of PBS and PBSA has no negative effect on the soil ecosystem and soil microbial community, these assumptions are based on very limited numbers of studies using lowresolution microbiological approaches $[4,12,25,26]$. High-resolution molecular approaches, such as nextgeneration sequencing should be applied to investigate the effect of bio-based and biodegradable plastics on microbial community composition and diversity [27].

In this study, we focus on the positive and negative aspects of bio-based and biodegradable plastic in agricultural soil systems. Specifically, we aimed to test the effects of PBSA on soil microbial diversity and community composition using high-resolution molecular technique (Illumina sequencing) targeting three microbial domains: archaea, bacteria, and fungi. We also tested the effects of PBSA addition along with nitrogen (N) fertilisation. Fertilisation is a common practice in agricultural sector that strongly affects soil microbial community composition and diversity [28]. We hypothesised that as a single factor, high load of PBSA does not significantly affect archaeal, bacterial, and fungal community composition and diversity; however, when combined with a second factor [here, synthetic $\mathrm{N}$ fertiliser, $\left(\mathrm{NH}_{4}\right)_{2} \mathrm{SO}_{4}$ ], PBSA might reduce microbial richness and significantly change the microbial community that favour nitrophilic fungi and bacteria. 


\section{Materials and methods}

\section{Experimental procedure: soil, PBSA, and experimental conditions}

To demonstrate the effects of PBSA on soil microbial diversity and community composition, we set up a PBSA decomposition experiment in the laboratory using soil from a plot under conventional farming and ambient climate treatment at the Global Change Experimental Facility [29], Bad Lauchstädt, Central Germany $\left(51^{\circ} 22^{\prime} 60 \mathrm{~N}, 11^{\circ} 50^{\prime} 60 \mathrm{E}, 118 \mathrm{~m}\right.$ a.s.l.). The soil was classified as a Chernozem (water holding capacity $=35 \%$, total organic $\mathrm{C}=2 \%, \mathrm{C}: \mathrm{N}$ ratio $=10, \mathrm{pH}=7.5)$. The conventional farming treatment at the study site integrates crop rotation (winter rape, winter wheat, and winter barley) and application of common fertilisers and pesticides, as described elsewhere [29]. Briefly, for winter rape, $\mathrm{N}$ fertiliser was applied three times (before seeding (40 kg/ha $\mathrm{N}$ as calcium ammonium nitrate together with $\mathrm{P}, \mathrm{K}$ and $\mathrm{S}$ fertilisers); at the start of the growing season $(100 \mathrm{~kg} /$ ha $\mathrm{N}$ as calcium ammonium nitrate together with $\mathrm{S}$ fertiliser); and at the start of shoot elongation $(60 \mathrm{~kg} / \mathrm{ha} \mathrm{N}$ as calcium ammonium nitrate)). For winter wheat and winter barley, $60 \mathrm{~kg} / \mathrm{ha} \mathrm{N}$ and $40 \mathrm{~kg} / \mathrm{ha} \mathrm{N}$ as calcium ammonium nitrate were applied at the start of the growing season and before shoot elongation, respectively [29]. Soil from winter barley was sampled, homogenised and subdivided in this study for four treatments: (1) control soil (soil without PBSA was incubated for 90 days in sterile glass jars which was used as controls); (2) control soil with $\left(\mathrm{NH}_{4}\right)_{2} \mathrm{SO}_{4}$ addition and without PBSA (control SN); (3) PBSA-soil (PS) treatment (soil with PBSA addition was incubated for 90 days in sterile glass jars), and (4) PBSA-soil-N (PSN) treatment (soil with PBSA and $\left(\mathrm{NH}_{4}\right)_{2} \mathrm{SO}_{4}$ addition was incubated for 90 days in sterile glass jars). Initial soil was also analysed along with soil samples from these four treatments and used as a reference. For PS, and PSN treatments, PBSA films (BioPBS FD92, PTT MCC Biochem Company Limited, Thailand; in the form of double-layer thin film with $50 \mu \mathrm{m}$ thickness, percent bio-based carbon $=35 \%$ ) were treated with $70 \%$ ethanol to sterilise the PBSA surface, cut into pieces (2-5 $\mathrm{mm} \times 2-5 \mathrm{~mm}), 1 \mathrm{~g}$ of which was weighed, and buried in a $100 \mathrm{ml}$ sterile glass jar containing $19 \mathrm{~g}$ soil (accounting for $15.68 \mathrm{~g}$ soil dry weight) from one of the two treatments: normal field soil (PS treatment) and field soil with $\left(\mathrm{NH}_{4}\right)_{2} \mathrm{SO}_{4}$ addition (PSN treatment), with five replicates for each treatment and PBSA: dried soil $=6 \% \mathrm{w} / \mathrm{w}$. Initial PBSA chemical and physical properties are available in Additional file 1: Appendix 1. In PSN treatment, $\left(\mathrm{NH}_{4}\right)_{2} \mathrm{SO}_{4}$ was directly added to the soil [1.4 mL of $1.42 \mathrm{M}\left(\mathrm{NH}_{4}\right)_{2} \mathrm{SO}_{4}, 0.055 \mathrm{~g} \mathrm{~N}$, equivalent to $280 \mathrm{~kg} \mathrm{~N}$ per hectare] to make $\mathrm{N}$ immediately available to soil microbes and to mimic fertilisation in agricultural systems. This $\mathrm{N}$ fertilisation rate is comparable to the highest rate of $\mathrm{N}$ fertilisation used in agroecosystems [30, 31], and it maintains a 10:1 C:N ratio in the soil-PBSA system. For PS and control treatments, $1.4 \mathrm{~mL}$ sterile Milli-Q water was added to achieve a soil water content equivalent to that in PSN treatment (17.5\%, accounting for $50 \%$ of the water holding capacity), which was considered to be at the field capacity of this soil under actual field conditions. We maintained the soil water contents of all treatments at $17.5 \%$ and air temperature at $22{ }^{\circ} \mathrm{C}$ during the 90-day experiment, which was conducted in dark. The experiment was conducted for 90 days at a constant soil moisture $(17.5 \% \mathrm{vol} / \mathrm{vol})$ and temperature $\left(22^{\circ} \mathrm{C}\right)$, which was long enough for PBSA to be degraded [8]. The lids of glass jars were manual opened and closed every 2 weeks under laminar flow to avoid anoxic conditions. The PBSA samples were separated from soil by sieving, washed, and dried at $60{ }^{\circ} \mathrm{C}$ for $48 \mathrm{~h}$ (until constant weight). Then the samples were weighted using five digits balance (Mewes Wägetechnik, Haldensleben, Germany). The plastic degradation was estimated by specific weight loss per $\mathrm{cm}^{2}$ as compared with original samples (5 replicates). After 90 days, PBSA samples were degraded under PS treatment (overall average mass loss $=13 \%$ ) and highly degraded under PSN treatment (72\% in three out of five samples, overall average mass loss $=60 \%$ ). Soil $\mathrm{pH}$ was investigated along with microbial diversity and community composition and was used as an explanatory variable for microbial responses. The $\mathrm{pH}$ of initial soil, control soil, control soil with $\left(\mathrm{NH}_{4}\right)_{2} \mathrm{SO}_{4}$, and soils under PS, and PSN treatments was measured in a 1:5 soil:water suspension.

\section{Analyses of microbiomes in PBSA and soils}

PBSA and soil microbiomes were characterised by $16 \mathrm{~S}$ rRNA gene-based and fungal internal transcribed spacer (ITS)-based amplicon sequencing on the Illumina MiSeq sequencing platform. Samples for DNA extraction from PBSA samples were processed by modifying a previously published protocol [32]. Briefly, we removed loosely adherent soil particles from PBSA samples by vortexing them in sterile phosphate-buffered saline $(0.01 \mathrm{M})$ for 5 min. PBSA samples were then submerged and shaken vigorously in $45 \mathrm{~mL}$ sterile Tween $(0.1 \%)$, and this step was repeated three times. The samples were then washed seven times using sterile water. Microbial biomass attached firmly to the PBSA sample was then subjected to DNA extraction using DNeasy PowerSoil Kit (Qiagen, Hilden, Germany) and a Precellys 24 tissue homogeniser (Bertin Instruments, Montigny-le-Bretonneux, France). Soil samples corresponding to PBSA samples were also subjected to DNA extraction using the DNeasy PowerSoil Kit with the same procedure used for PBSA samples, 
according to the manufacturer's instructions. The presence and quantity of genomic DNA was checked using NanoDrop ND-1000 spectrophotometer (Thermo Fisher Scientific, Dreieich, Germany), and the extracts were stored at $-20{ }^{\circ} \mathrm{C}$. For construction of the bacterial and archaeal amplicon libraries, the $16 \mathrm{~S}$ rRNA gene V4 region was amplified using the universal bacterial/archaeal primer pair 515F (5'-GTGCCAGCMGCCGCGGTAA-3') and 806R (5'-GGACTACHVGGGTWTCTAAT-3')[33] with Illumina adapter sequences. For establishing fungal amplicon libraries, the fungal ITS2 gene was amplified using the fungal primer pair fITS7 (5'-GTGARTCAT CGAATCTTTG-3') [34] and ITS4 primer ( $5^{\prime}$-TCCTCC GCTTATTGATATGC-3') [35] with Illumina adapter sequences. Amplifications were performed using 20- $\mu \mathrm{L}$ reaction volumes with $5 \times$ HOT FIRE Pol Blend Master Mix (Solis BioDyne, Tartu, Estonia). The amplified products were visualised by gel electrophoresis and purified using an Agencourt AMPure XP kit (Beckman Coulter, Krefeld, Germany). Illumina Nextera XT Indices were added to both ends of the bacterial and fungal amplicons. The products from three technical replicates were then pooled in equimolar concentrations. Paired-end sequencing $(2 \times 300 \mathrm{bp})$ was performed on the pooled PCR products using a MiSeq Reagent kit v3 on an Illumina MiSeq system (Illumina Inc., San Diego, CA, United States) at the Department of Soil Ecology, Helmholtz Centre for Environmental Research, Germany. The raw $16 \mathrm{~S}$ and ITS rRNA gene sequences were deposited in the National Center for Biotechnology Information (NCBI) Sequence Read Archive under the accession number PRJNA702448.

The $16 \mathrm{~S}$ and ITS rDNA sequences corresponding to the forward and reverse primers were trimmed from the demultiplexed raw reads using cutadapt [36]. Paired-end sequences were quality-trimmed, filtered for chimeras, and merged using the DADA2 package [37] through the pipeline dadasnake [38]. Assembled reads fulfilling the following criteria were retained for further analyses: minimum lengths of 200 and 150 nt forward and reverse sequences (bacteria) or $70 \mathrm{nt}$ (fungi), quality scores at least equal to 15 (bacteria) or 9 (fungi) with maximum expected error score of 2 (bacteria) and 5 (fungi) for forward and reverse sequences and no ambiguous nucleotides. Merging was conducted with 2 mismatches allowed and a minimum overlap of 20 nucleotides required for bacterial and fungal sequences, respectively. High-quality reads were clustered into 6514 and 788 amplicon sequence variants (ASVs) for prokaryotes and fungi, respectively, after chimera removal. The SILVA SSU database v. 138 was used for taxonomic classification of the bacterial and archaeal ASVs. Fungal ASVs were classified against the UNITE v7.2 database [39].
Both sets of ASVs were classified using the Bayesian classifier as implemented in the mothur classify.seqs command, with a cut-off of 60 . The ASV method is used to infer the biological sequences in the sample, as described previously [40]. Rare ASVs (singletons), which potentially represent artificial sequences, were removed. Finally, we obtained the minimum sequencing depths of 34,856 and 46,400 sequences per sample for the prokaryotic and fungal datasets, respectively. Relative abundance and presence/absence datasets for archaea, bacteria, and fungi were used in the data analyses. Microbial taxonomic and relative abundance information is provided in Additional file 2: Tables S1, S2, and S3. The rarefaction curves of all the samples reached saturation (Additional file 1: Fig. S1); thus, we used the observed richness as a measure of microbial diversity. We checked the taxonomic annotations of the top 40 most abundant fungal ASVs used in this study by conducting BLAST searches against the current version of UNITE (version: 8.2; 2020-01-15), and the UNITE species hypotheses [41] were used for all ASVs. The fungal ecological function of each ASV was determined using FUNGuild [42]. We verified taxonomic annotations at the species level for the 40 most abundant bacterial ASVs from in this study by conducting BLAST searches against the current version of NCBI (version: 2.11.0). Only the top match with $99 \%-100 \%$ identity was included. Potential functions (animal and human pathogen, biological control, denitrifying bacteria, plant growth promotion, $\mathrm{N}$ fixing, opportunistic human pathogen, plant pathogen, potential lipase producer, potential PBS and PBSA degrader, saprotroph, and sulphur cycling) of archaea, bacteria, and fungi were manually assigned using publications listed in the Web of Science (ISI Web of Knowledge) [43].

\section{Statistical analysis}

The effects of soil treatments on archaeal, bacterial, and fungal ASV richness in soil and PBSA samples were analysed using analysis of variance (ANOVA), incorporating the Jarque-Bera JB test for normality and Levene's test to assess the equality of group variances. The effects of soil treatments on archaeal, bacterial, and fungal community compositions in soil and PBSA samples were visualised and analysed using non-metric multidimensional scaling, permutational multivariate ANOVA (PERMANOVA), and analysis of similarities (ANOSIM), based on presence-absence data and the Jaccard distance measure; for ANOSIM, over 999 permutations were run. As relative abundance data from metabarcoding may contain some biases [44], we analysed the microbial community composition mainly using presence/absence data sets. The effects of soil treatments on soil $\mathrm{pH}$ were analysed using the Kruskal-Wallis test. The relationships between 
$\mathrm{pH}$ and archaeal, bacterial, and fungal richness were analysed using Pearson's correlation coefficient. All statistical analyses were performed using PAST version 2.17. The amounts of variation in archaeal, bacterial, and fungal community compositions, explained by various factors, were estimated through variation partitioning using the Vegan package in $\mathrm{R}$ [45].

\section{Results}

\section{General information regarding microbial communities associated with PBSA degradation}

We analysed the archaeal, bacterial, and fungal communities that were adhered to PBSA films in soils with and without $\left(\mathrm{NH}_{4}\right)_{2} \mathrm{SO}_{4}$ addition (PSN and PS treatments, respectively), those present in the soil surrounding the PBSA in the aforementioned treatments, and those present in soil not treated with PBSA (control soil and control SN treatments) after 90 days of incubation; for comparison, we also analysed the communities present in the initial soil without incubation (initial soil treatment). Taxonomic resolution was conducted at the ASV level (Additional file 2: Tables S1, S2, and S3). In total, we detected $27,6,487$, and 788 archaeal, bacterial, and fungal ASVs, respectively, across all PBSA and soil microbial communities (Additional file 2: Tables S1, S2, and S3). The archaeal, bacterial, and fungal ASVs corresponded to 3, 418, and 164 genera, respectively. Among these, we detected 7 (26\% of total archaeal ASVs), 2,113 (33\% of total bacterial ASVs), and 170 ASVs (22\% of total fungal ASVs) for archaea, bacteria, and fungi in PBSA, respectively (Additional file 2: Tables S1, S2, and S3). In soil samples from PS and PSN treatments, we detected 20 (74\% of total archaeal ASVs), 5,429 (84\% of total bacterial ASVs), and 313 ASVs (40\% of total fungal ASVs) for archaea, bacteria, and fungi, respectively (Additional file 2: Tables S1, S2, and S3). The relative archaeal (ASV level), bacterial (phylum level), and fungal (class level) abundances are shown in Fig. 1. Briefly, microbial community composition (at the coarse taxonomic level) of initial soil and control soils were comparable for archaeal (dominated by Nitrososphaeraceae), bacteria (dominated by Proteobacteria), and fungi (dominated by Sordariomycetes) (Fig. 1). While pure PBSA addition did not significantly change archaeal community composition, it increased relative abundance of Proteobacteria and strongly reduced abundance of Sordariomycetes (Fig. 1). Adding $\left(\mathrm{NH}_{4}\right)_{2} \mathrm{SO}_{4}$ into PBSA-soil system increased Proteobacteria and Sordariomycetes (Fig. 1). The microbial community composition at coarse taxonomic level of PBSA was significantly different from those of the surrounding soil (Fig. 1). PSN treatment significantly reduced microbial diversity on PBSA.

\section{Effects of PBSA on microbial ASV richness}

Both prokaryotic (archaeal and bacterial) and fungal ASV richness in the control soil without PBSA (control S) and control soil with $\left(\mathrm{NH}_{4}\right)_{2} \mathrm{SO}_{4}$ addition (control SN) were similar to those in the initial soil (Fig. 2). Bacterial ASV richness in soil under PS treatment was not significantly affected by PBSA, while archaeal ASV richness was slightly decreased (by 13\%) and fungal ASV richness was strongly reduced by approximately $45 \%$ (Fig. 2a, c, e). $\left(\mathrm{NH}_{4}\right)_{2} \mathrm{SO}_{4}$ as a single factor (control SN treatment) did not significantly affect the microbial richness. Contrarily, adding $\left(\mathrm{NH}_{4}\right)_{2} \mathrm{SO}_{4}$ into PBSA-soil system caused a significant reduction in archaeal, bacterial and fungal ASV richness in soil under PSN treatment by $31 \%-79 \%$. The richness of bacteria and fungi colonising PBSA in the PS treatment accounted for $60 \%$ and $43 \%$, respectively, of the richness of the surrounding soil (Fig. 2). Moreover, bacterial and fungal ASV richness in the communities adhered to PBSA following PSN treatment accounted for only $14 \%$ and $38 \%$, respectively, of the corresponding richness of the soil microbiome (Fig. 2).

\section{Effects of PBSA on soil microbial community composition and activity}

Both prokaryotic and fungal community compositions in control soil were almost identical to those in the initial soil (Fig. 3a, c, e). We found small but significant changes in bacterial and fungal community compositions in soils under control SN and PS treatment but not in archaeal community composition. After adding PBSA, the relative abundance of Proteobacteria (30.6\%, 2.7\% contributed by Bradyrhizobium ASV 15) in PS-treated soil slightly increased compared with its abundance in control soils, whereas the relative abundance of Actinobacteriota and Acidobacteriota slightly decreased (Fig. 1b). For fungi, there were large changes in the dominant fungal classes in PS-treated soil compared with its abundance in initial

(See figure on next page.)

Fig. 1 Composition of the archaeal (a) (ASV level), the bacterial (b) (phylum-level, considering only phyla with $\geq 10$ ASVs or relative abundances $\geq 1 \%$, the rest of the bacterial phyla were pooled as "others") and the fungal (c) (class-level, considering only classes with $\geq 10$ ASVs or relative abundances $\geq 1 \%$, the rest of the fungal classes were pooled as "others") communities associated with the degradation of a bio-based and biodegradable poly(butylene succinate-co-adipate) (PBSA) based on relative abundance. Data are presented for initial soil (initial S), control soils (control S), control soils with $\left(\mathrm{NH}_{4}\right)_{2} \mathrm{SO}_{4}$ addition (control SN), soils under PS treatment (S-PS), soils under PSN treatment (S-PSN), PBSA plastics under PS treatment (P-PS), and PBSA plastics under PSN treatment (P-PSN) 

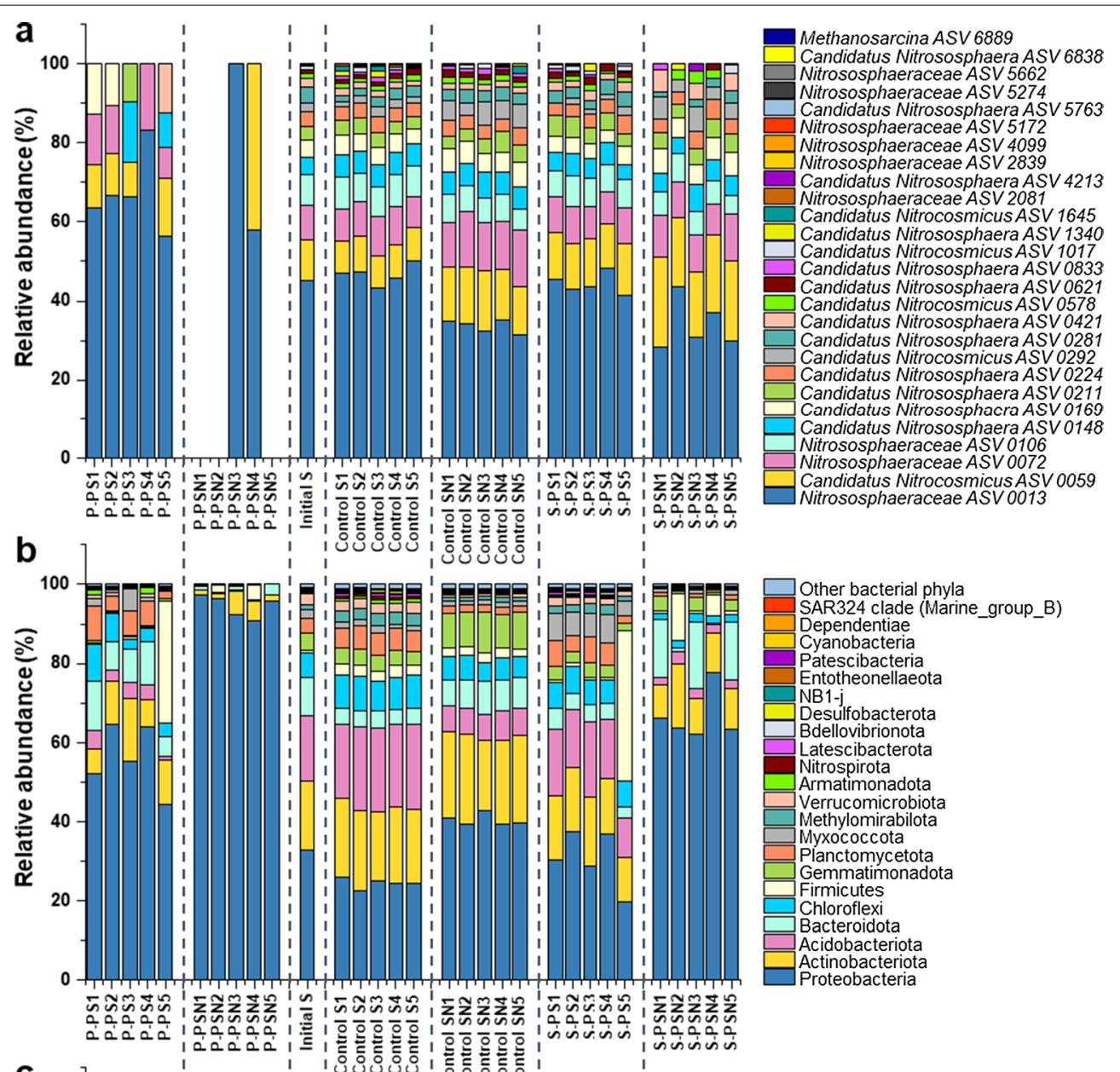
$\square$ Other bacterial phyla
SAR324 clade (Marine_group_B)
Dependentiae

Cyanobacteria

Patescibacteria

Entoth

NB1-j ${ }^{\text {Desulfobacterota }}$

Bdellovibrionota

Latescibacterota

Nitrospirota

Armatimonadota

Verrucomicrobiota

Methylomirabilota

Myxococcota

Gemmatimonadota

Firmicutes

Chloroflexi

Bacteroidota

Acidobacteriota

Actinobacteriota

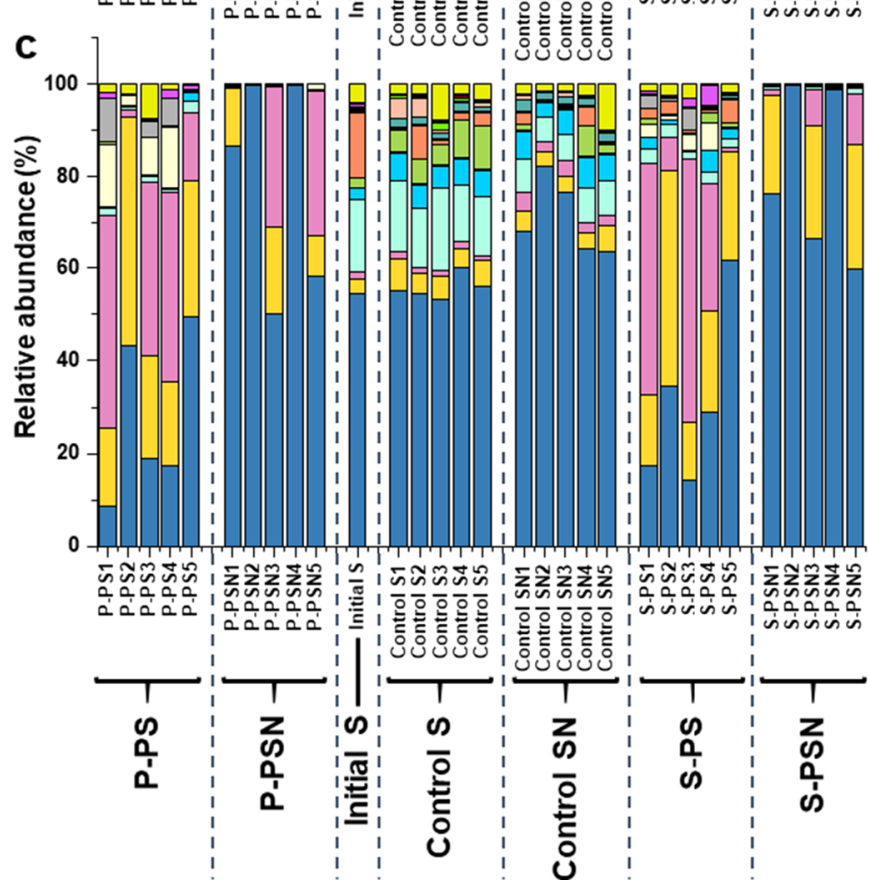

$\square$ Other Fungi

Other Chytridiomycota

Other Basidiomycota

ther Ascomycota

Spizellurriyceles

Pezizomycetes

Tremellomycetes

Rhizophlyctidomycetes

Agaricomycetes

Orbiliomycetes

Dotiomycetes

Eurotiomycetes

Sordariomycetes 

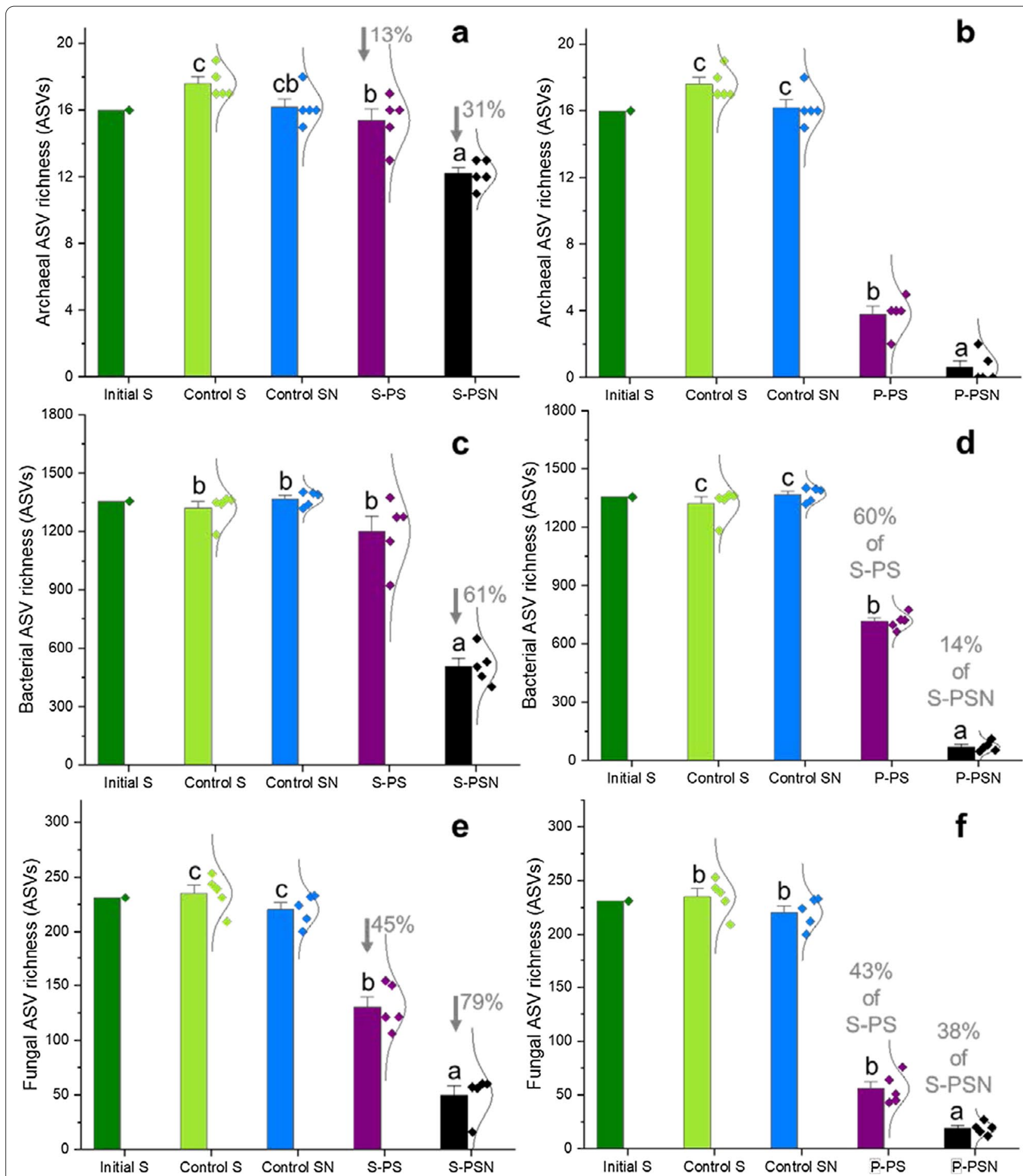

Fig. 2 ASV richness (number of ASVs) for archaea $(\mathbf{a}, \mathbf{b})$, bacteria (c, $\mathbf{d})$ and fungi $(\mathbf{e}, \mathbf{f})$ in soil (left) and on PBSA (right) samples. Details of the treatment abbreviations can be found in the legend of Fig. 1

and control soils. Eurotiomycetes $(24.0 \%, 20.6 \%$ contributed by Exophiala equina ASV 02) and Leotiomycetes $(28.6 \%, 23.1 \%$ contributed by Tetracladium furcatum
ASV 03) were co-dominant with Sordariomycetes (31.4\%, 9.5\% contributed by Ilyonectria macrodidyma ASV 07 and $4.7 \%$ contributed by Chaetomium globosum ASV 09), 
whereas Dothideomycetes almost disappeared from the PS-treated soil (Fig. 1c).

Adding $\left(\mathrm{NH}_{4}\right)_{2} \mathrm{SO}_{4}$ together with PBSA strongly shifted the microbial community composition of soil under PSN treatment from that of the initial, control soils and control soils with $\left(\mathrm{NH}_{4}\right)_{2} \mathrm{SO}_{4}$ addition. Archaeal, bacterial and fungal community compositions in soil were more sensitive to the combination of the two amendment additions (PBSA and $\left(\mathrm{NH}_{4}\right)_{2} \mathrm{SO}_{4}$ addition) (Figs. 1, 3). After adding $\left(\mathrm{NH}_{4}\right)_{2} \mathrm{SO}_{4}$ and PBSA, the abundance of Candidatus Nitrocosmicus ASV 59 in the soil of the PSN treatment increased compared with its abundance in initial and control soils, whereas the abundance of Nitrososphaeraceae ASV 13 slightly decreased, and some other archaeal ASVs disappeared. Strong hyperdominant patterns were observed for both bacterial and fungal communities in PSN-treated soil. We found that only Proteobacteria (66.6\%, 20\% contributed by Achromobacter insolitus ASV 02) was dominant in the bacterial community and that Sordariomycetes $(80.3 \%, 43.0 \%$ contributed by Fusarium solani ASV 01 and 10.2\% contributed by Clonostachys rosea ASV 11) were dominant in the fungal community in PSN-treated soil (Fig. 1b, c). Interestingly, in two of five soil samples under PSN treatment, PBSA decomposition rates were lower than those of the other three replicates, whereas Bacteroidota (contributed by Chitinophaga ASV 41) and Eurotiomycetes (contributed by E. equina ASV 02) almost completely disappeared (Fig. 1b, c).

\section{Different colonisers of PBSA under PS and PSN treatments}

The compositions of archaeal, bacterial, and fungal communities in PBSA receiving PS and PSN treatments were significantly different from those of their soil counterparts (Additional file 1: Table S4). Among the total 27 archaeal ASVs, only seven were present on PBSA under PS treatment. Among these, Nitrososphaeraceae ASV 13, Candidatus Nitrocosmicus ASV 59, and Nitrososphaeraceae ASV 72 were dominant (Fig. 1a and Additional file 2: Table S1). The bacterial community in the PBSA samples under PS treatment was dominated by Proteobacteria (56.1\%, $7.5 \%$ contributed by Caulobacter rhizosphaerae ASV 08, 3.5\% contributed by Azotobacter chroococcum ASV 18) with a small contribution from Actinobacteriota (10.3\%, 1.1\% contributed by Agromyces ramosus ASV 30$)$ and Bacteroidota (8.7\%, $1.1 \%$ contributed by Ohtaekwangia ASV 97) (Figs. 1b, 4 and Additional file 2: Table S2). In the fungal community, Leotiomycetes $(28.3 \%, 22.8 \%$ contributed by Tetracladium furcatum ASV 03), Eurotiomycetes (27.2\%, 22.6\% contributed by E. equina ASV 02) and Sordariomycetes (27.6\%, $18.1 \%$ contributed by I. macrodidyma ASV 07) were co-dominant in the PBSA samples under PS treatment (Figs. 1c, 5 and Additional file 2: Table S3). For PBSA under PSN treatment, only Nitrososphaeraceae ASV 13 was detected in two of five independent PBSA replicates and Candidatus Nitrocosmicus ASV 59 in one replicate, whereas in the other three replicates, archaea were completely absent (Fig. 1a). In the PSN treatment, only a few bacterial phyla and fungal classes could colonise the PBSA (Fig. 1b, c). Proteobacteria (94.6\%, 19.4\% contributed by Stenotrophomonas maltophilia ASV 03, $18.9 \%$ contributed by $A$. insolitus ASV 02 and $15.3 \%$ contributed by Achromobacter denitrificans ASV 04) and Sordariomycetes $(78.9 \%, 49.1 \%$ contributed by $F$. solani ASV 01 and 14\% contributed by C. rosea ASV 11) dominated the bacterial and fungal communities, respectively, of PBSA samples under PSN treatment (Figs. 1b, c, 4, 5, Additional file 2: Tables S2 and S3).

\section{Soil $\mathrm{pH}$ response to PBSA addition and links to microbial community composition and richness}

The initial soil $\mathrm{pH}$ of 7.5 slightly decreased when $\left(\mathrm{NH}_{4}\right)_{2} \mathrm{SO}_{4}$ was added ( $\mathrm{pH}$ 7.3) (Additional file 1: Fig. S2a). After 90 days of incubation, $\mathrm{pH}$ values in the control soil and PS-treated soil were similar to the initial soil $\mathrm{pH}$. Contrarily, soil $\mathrm{pH}$ after 90 days of incubation significantly decreased under control SN and PSN treatment ( $\mathrm{pH}$ value 6.7 and 6.3, respectively). $\mathrm{pH}$ values were significantly positively correlated with archaeal, and bacterial richness $(R=0.54-0.55, P=0.011-0.014$, Additional file 1: Fig. S2b, c). We found no correlation between $\mathrm{pH}$ values and fungal richness (Additional file 1: Fig. S2d). Overall, treatments explained $13 \%, 23 \%$, and $28 \%$ of variations in archaeal, bacterial, and fungal community composition, respectively (Additional file 1: Fig. S3a-c). PBSA explained $54 \%, 35 \%$, and $64 \%$ of the total explainable variation in archaeal, bacterial, and fungal community composition, respectively. The addition of $\left(\mathrm{NH}_{4}\right)_{2} \mathrm{SO}_{4}$ did not explain archaeal community composition, but explain $13 \%$, and $11 \%$ of the total explainable variation in bacterial, and fungal community composition. $\mathrm{pH}$ alone

(See figure on next page.)

Fig. 3 Non-metric multidimensional scaling (NMDS) ordinations of archaeal (a, b), bacterial (c, d) and fungal (e, $\mathbf{f})$ community compositions in soil based on presence/absence data and the Jaccard dissimilarity measure. Data are presented for initial soil (0), control soil (1), control SN (2), and PBSA and soils from the PS (3), and PSN (4) treatments. Details of the treatment abbreviations can be found in the legend of Fig. 1. PERMANOVA and ANOSIM results are provided in Additional file 1: Table S4 

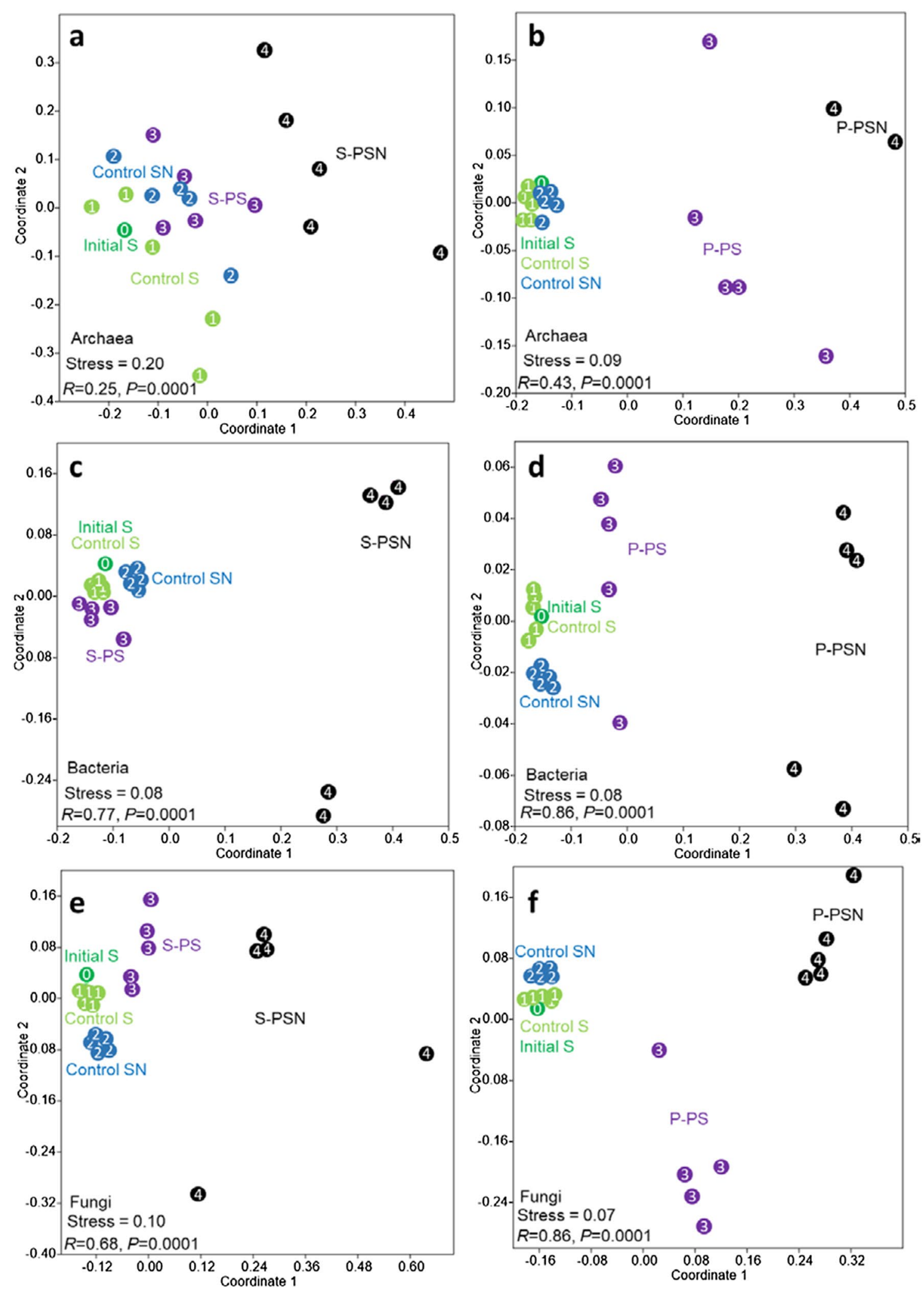

Fig. 3 (See legend on previous page.) 


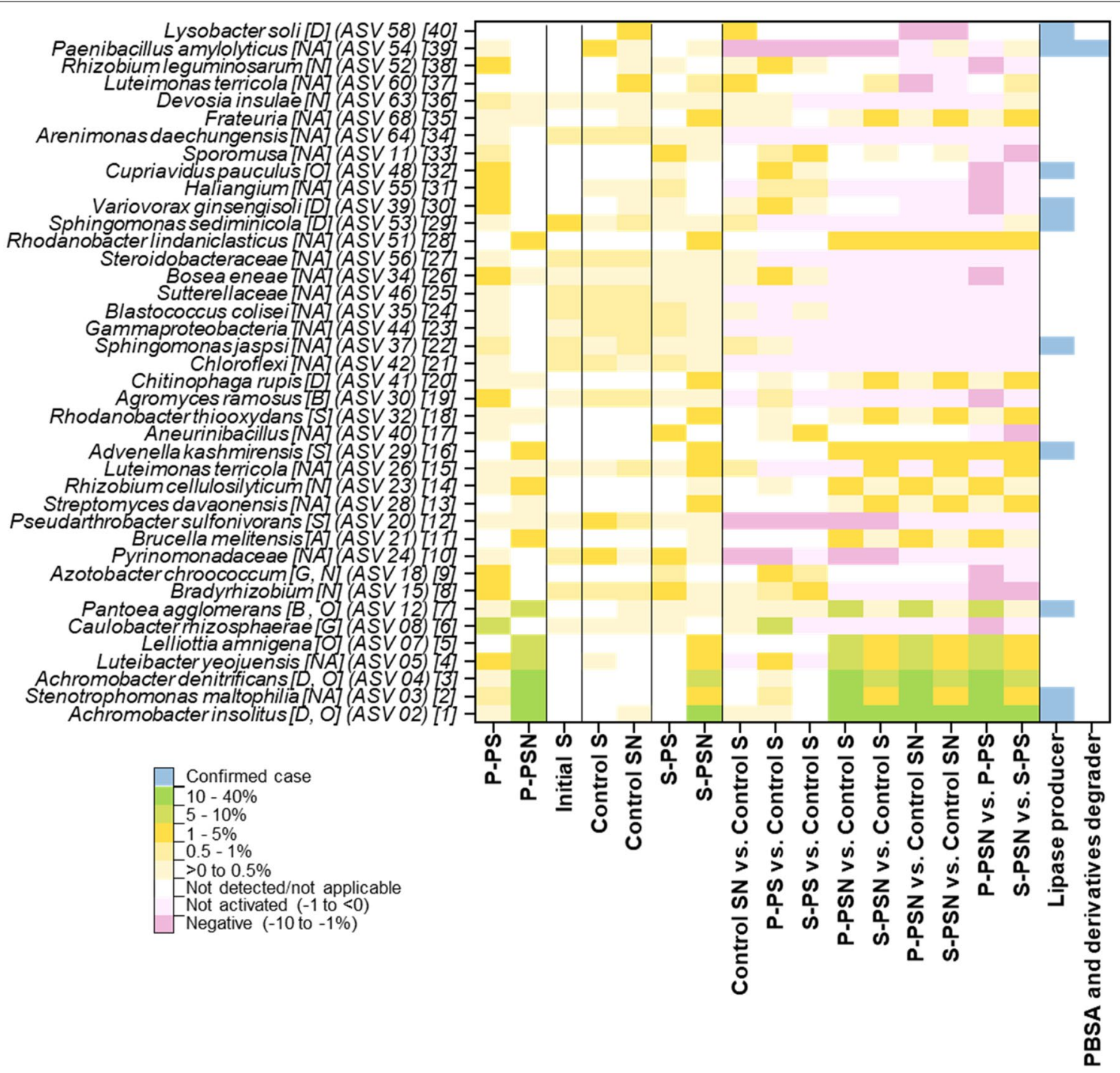

Fig. 4 Top-40 bacterial ASVs that had the highest relative abundances in all treatments (initial soil, control soil, control SN, and PBSA and soils in PS, and PSN treatments). The enrichment or the decline of bacterial ASVs in PBSA and soil samples from the PS and PSN treatment were compared with those in the control soil and control soil with $\left(\mathrm{NH}_{4}\right)_{2} \mathrm{SO}_{4}$ addition. The last two columns indicate bacterial ASVs that have been reported to produce lipase enzyme and to degrade PBS and its derivatives in previous studies. The letters in the square parentheses indicate the functions of each ASV: A: animal and human pathogen, B: biological control, D: denitrifying bacteria, G: plant growth promotion, N: N fixing, NA: not applicable, O: opportunistic human pathogen, P: plant pathogen, and S: sulphur cycling. The number in the square parentheses indicates the ranking of each ASV among the top-40 ASVs. Details of the treatment abbreviations can be found in the legend of Fig. 1

did not explain the microbial community compositions. However, the combinations of $\mathrm{pH}$ and $\left(\mathrm{NH}_{4}\right)_{2} \mathrm{SO}_{4}$ addition explained $31 \%, 43 \%$, and $21 \%$ of the total explainable variation in archaeal, bacterial, and fungal community composition, respectively.

\section{Potential lipase-producing and PBS/PBSA-degrading microbes}

Considering the 40 most abundant bacteria, potential lipase-producing bacteria were almost absent or were detected in low relative abundance in the initial, control soils and control soils with $\left(\mathrm{NH}_{4}\right)_{2} \mathrm{SO}_{4}$ addition, whereas potential PBS-degrading bacteria were not detected in the initial soil (Fig. 4). In control soils and control soils with $\left(\mathrm{NH}_{4}\right)_{2} \mathrm{SO}_{4}$ addition, only Paenibacillus amylolyticus ASV 54 (a potential lipase producer and potential PBS degrader) $[1,46]$ was detected with $1.8 \%$ and $0.006 \%$ relative abundance, respectively. In PS- and PSNtreated soils, P. amylolyticus was not detected or detected at very low relative abundance $(\leq 0.01 \%)$. Potential 


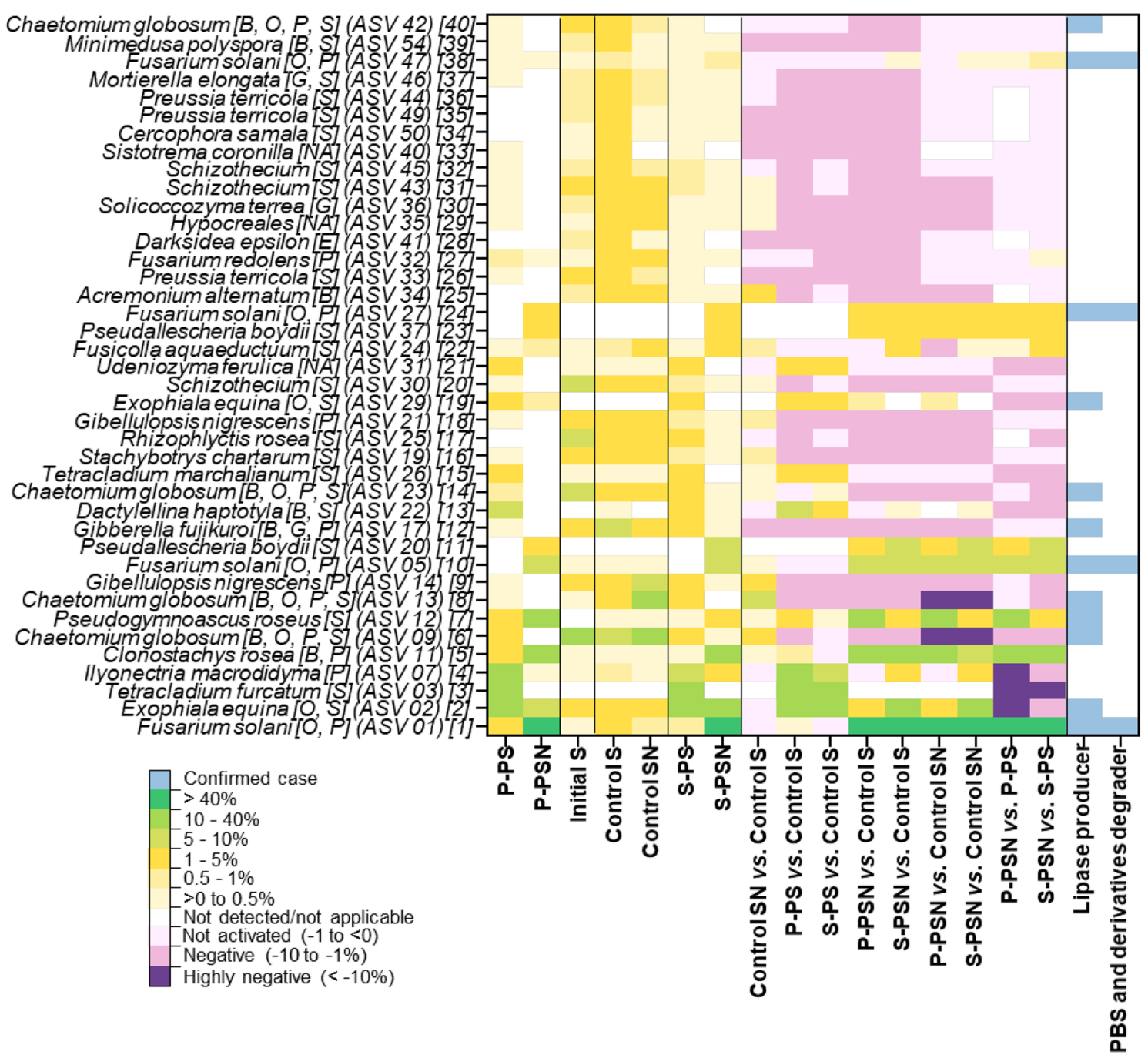

Fig. 5 Top-40 fungal ASVs that had the highest relative abundances in all treatments (initial soil, control soil, control SN, and PBSA and soils in the PS, and PSN treatments). The enrichment or the decline of fungal ASVs in PBSA and soil samples from the PS and PSN treatment were compared with those in the control soil and control soil with $\left(\mathrm{NH}_{4}\right)_{2} \mathrm{SO}_{4}$ addition. The last two columns indicate fungal ASVs that have been reported to produce lipase enzyme and to degrade PBS and its derivatives in previous studies. The letters in the square parentheses indicate the functions of each ASV: B: biological control, E: endophyte, G: plant growth promotion, NA: not applicable, O: opportunistic human pathogen, P: plant pathogen, and S: saprotroph. The number in the square parentheses indicates the ranking of each ASV among the top-40 ASVs. Details of the treatment abbreviations can be found in the legend of Fig. 1

lipase-producing bacteria were found to be associated with both soil and PBSA samples across all other treatments (PS, and PSN treatments). Most of them were more enriched on PBSA than in soil from the same treatment. However, the community of these potential lipaseproducing and PBS-degrading bacteria differed among treatments. After incorporating PBSA into soil, five out of 10 potential lipase-producing bacteria were detected in PS-treated soil at very low relative abundances $(\leq 0.3 \%)$. In PBSA samples under PS treatment, eight out of 10 potential lipase-producing bacteria were detected, and
Cupriavidus pauculus ASV 48, Variovorax ginsengisoli ASV 39 were enriched. In the PSN treatment, $A$. insolitus ASV 02 was highly enriched in both soil and PBSA samples. Pantoea agglomerans ASV 12, and Stenotrophomonas maltophilia ASV 03 were detected in soil and highly enriched in PBSA samples under PSN treatment.

Among the 40 most abundant fungi, all potential PBSdegrading fungi were $F$. solani ASV 01, ASV 05, ASV 27, and ASV 47 [47] (Fig. 5). F. solani was also reported to potentially produce lipase [48]. In the initial, control soils and control soils with $\left(\mathrm{NH}_{4}\right)_{2} \mathrm{SO}_{4}$ addition, three 
out of four potential PBS-degrading F. solani ASVs were detected with $0.04-1.4 \%$ relative abundance. Under PS treatment, two out of four F. solani ASVs were found to be associated with both soil and PBSA samples (0.08$1.7 \%$ relative abundance). Under PSN treatment, F. solani ASV 01 was highly enriched in both soil and PBSA samples with relative abundances of 43-49\%. The community of other potential lipase-producing fungi also differed among the different treatments. Chaetomium globosum were the most abundant in the initial (11.9\%), control soils $(5.7 \%)$ and control soils with $\left(\mathrm{NH}_{4}\right)_{2} \mathrm{SO}_{4}$ addition (10.5\%). Under PS treatment, E. equina ASV 02 was enriched in both soil and PBSA samples (21-23\%). Under the PSN treatment, E. equina ASV 02 and Pseudogymnoascus roseus ASV 12 were enriched in both soil and PBSA samples (7-14\% and 4-12\%, respectively).

\section{Beneficial and pathogenic microorganisms associated with PBSA: top 40 bacteria and fungi}

We found that both beneficial and pathogenic microbes colonised PBSA samples, and they were listed among the top-40 most abundant bacteria and fungi (Figs. 4, 5). Three main groups of potentially beneficial bacteria associated with PBSA were as follows: (i) biological control agents $(A$. ramosus, and $P$. agglomerans), (ii) plant growth-promoting microorganisms (A. chroococcum and C. rhizosphaerae), and (iii) N fixers (A. chroococcum, Bradyrhizobium, Devosia insulae, Rhizobium cellulosilyticum, and R. leguminosarum). Among the beneficial bacteria, $C$. rhizosphaerae (7.5\%), A. ramosus, A. chroococcum, Bradyrhizobium, and R. leguminosarum were enriched (1.1-7.5\%) on PBSA under PS treatment. Most beneficial bacteria, especially $\mathrm{N}$-fixing bacteria (three of five ASVs), were suppressed in PBSA under PSN treatment (Fig. 4). Only a biological control agent (P. agglomerans) was enriched in PBSA under PSN treatment. In fungi, we detected only two potential beneficial groups associated with PBSA: (i) biological control agents (Chaetomium globosum, C. rosea, Dactylellina haptotyla, Gibberella fujikuroi, and Minimedusa polyspora) and (ii) plant growth promoters (G. fujikuroi, Mortierella elongata and Solicoccozyma terrea). Among them, D. haptotyla was suppressed in PBSA under PSN treatment (Fig. 5). Only one biological control agent (C. rosea) was enriched in PBSA under PSN treatment.

Opportunistic human pathogenic bacteria and plant pathogenic fungi were the frequently detected pathogenic microorganisms in PS-treated PBSA samples. Opportunistic human pathogenic bacteria dominated the 40 most abundant bacterial ASVs, and these included A. denitrificans, A. insolitus, C. pauculus, Lelliottia amnigena and $P$. agglomerans. Among them, only $C$. pauculus was enriched in PS-treated PBSA samples, although it was not detected in either the initial or both control soils (control
$\mathrm{S}$ and SN). Furthermore, A. denitrificans and A. insolitus (not detected in initial and control soils and almost absent in control soil with $\left(\mathrm{NH}_{4}\right)_{2} \mathrm{SO}_{4}$ addition) was highly enriched in PSN-treated PBSA samples (15\% and $19 \%$, respectively). Apart from opportunistic pathogenic bacteria, there was an animal and human pathogen (Brucella melitensis) that was only detected in PSN-treated PBSA sample, where it was abundant. The 40 most abundant fungi were dominated by plant pathogens (Fig. 5). Among them, I. macrodidyma was enriched after PBSA was incorporated into the soil (PS treatment). PSN treatment markedly enriched the relative abundances of $C$. rosea and $F$. solani, whereas it significantly suppressed those of I. macrodidyma. Some plant pathogens, such as C. globosum and F. solani were also classified as opportunistic human pathogens. In this study, we found that individual bacterial and fungal ASVs may represent more than one function, even the opposite one. For example, $P$. agglomerans is an opportunistic pathogen that also helps in biological control, and C. rosea is classified as either a biological control or a plant pathogen depending on the plant species being considered.

\section{Effects of PBSA on beneficial and pathogenic microbes in soil}

PBSA not only offers a habitat for beneficial and pathogenic microbes, but also alters the relative abundances of such microbes in soils. The relative abundances of these microbes detected on PBSA and in soil did not always correspond with each other. We detected three patterns: (i) enriched both in soil and in PBSA [bacteria: Bradyrhizobium (N fixation), fungi: Dactylellina haptotyla (biological control, and saprotroph), E. equina (opportunistic human pathogen and saprotroph), and I. macrodidyma (plant pathogen)]; (ii) enriched only on plastic but not in soil [bacteria: A. ramosus (biological control), C. rhizosphaerae (plant growth-promoting bacteria), C. pauculus (opportunistic human pathogen), R. leguminosarum (N fixation), fungi: C. rosea (biological control and plant pathogen)] and (iii) enriched only in soil but not on plastic [fungi: A. alternatum (biological control), G. fujikuroi (biological control, plant growth promoter and plant pathogen), Gibellulopsis nigrescens (plant pathogen)]. Addition of $\left(\mathrm{NH}_{4}\right)_{2} \mathrm{SO}_{4}$ together with PBSA (PSN treatment) highly enriched both bacteria $[A$. denitrificans and $A$. insolitus (denitrification and opportunistic human pathogens)] and fungi [C. rosea (biological control and plant pathogen) and F. solani (plant pathogen and opportunistic human pathogen)] both in soil and on PBSA. E. equina (opportunistic human pathogen and saprotroph) was relatively resistant to the combined effect of $\left(\mathrm{NH}_{4}\right)_{2} \mathrm{SO}_{4}$ and PBSA addition 
as its relative abundance was not significantly different between PS- and PSN-treated soils.

\section{Discussion \\ How soil and soil microorganisms respond to PBSA addition?}

We are able to maintain richness and community compositions of soil prokaryotes (archaeal and bacterial) and fungi in control treatment under laboratory system for 90 days to be resemble to those of the initial field soil, thus changes in microbial communities observed in our experiment are highly representative by our treatment settings. The decline in the soil microbial richness under PBSA addition varied among microbial kingdoms in the following order: fungi $>$ archaea $>$ bacteria. Fungi were the most sensitive, as their diversity largely declined (45\%) and their community composition was significantly changed by PBSA addition. Bacterial richness was resistant to PBSA, but bacterial community composition significantly changed by gaining $\mathrm{N}$-fixing bacteria, such as A. chroococcum, $R$. leguminosarum, and Bradyrhizobium sp., under PBSA addition. Contrastingly to bacterial and fungal communities, the archaeal community composition was resistant to PBSA but the archaeal richness significantly reduced. $\mathrm{pH}$ did not explain the changes in soil archaeal and fungal diversity and bacterial and fungal community compositions in PS-treated soil compared with those in control soil as the $\mathrm{pH}$ values in these two treatments were similar. We suggest that the presence of PBSA promotes specific fungi (especially, E. equina, and I. macrodidyma) that may outcompete other fungi and eventually affect fungal-bacterial interactions. Strong inter-kingdom relationships between bacteria and fungi, especially between $\mathrm{N}$-fixing bacteria and fungi, in PBSA were demonstrated in soil under field conditions [49]. Indeed, we found that Bradyrhizobium sp. was the most enriched taxa in soil after PBSA was incorporated for 90 days, which occurred concurrently with an increase in the relative abundance of Exophiala spp., known as efficient lipase-producing fungi [50].

The combination of the two amendment additions, PBSA and $\left(\mathrm{NH}_{4}\right)_{2} \mathrm{SO}_{4}$ fertiliser, caused a significant decline in diversity and changed the community composition of all three kingdoms. This can be partly explained by the alteration of soil $\mathrm{pH}$ caused by the addition of $\left(\mathrm{NH}_{4}\right)_{2} \mathrm{SO}_{4}$. Ammonium sulphate has a pH of 5.5 and immediately changed soil $\mathrm{pH}$ (by 0.2 unit) under $\left(\mathrm{NH}_{4}\right)_{2} \mathrm{SO}_{4}$ treatment. In soil, ammonium $\left(\mathrm{NH}_{4}^{+}\right)$ions are oxidised to nitrate $\left(\mathrm{NO}_{3}{ }^{-}\right)$by nitrification, causing the release of $\mathrm{H}^{+}$ions, leading to a reduction in soil $\mathrm{pH}$ [51]. It has been previously reported that $\left(\mathrm{NH}_{4}\right)_{2} \mathrm{SO}_{4}$ application at a rate of $210 \mathrm{~kg} / \mathrm{ha}$ (which is similar to the application rate in our study) causes a reduction in $\mathrm{pH}$ from 5.8 to 5.2 in rice field soil (Inceptisols) [51]. In our system, there were no plants to neutralise the $\mathrm{H}^{+}$from nitrification process, which made the $\mathrm{pH}$ decrease approximately 1.2 units from 7.5 to 6.3. Soil acidification is known to negatively affect a broad range of soil organisms, especially bacteria [52]. In our experiment, however, the soil $\mathrm{pH}$ (except two replicates from PSN treatment, $\mathrm{pH}=5.8$ ) remained close to physiological optimum (6-6.5), therefore microorganisms were not subjected to the acidic stress. The microbial community composition was also shifted towards nitrophilic microorganisms, which can outcompete other microbes under high $\left(\mathrm{NH}_{4}\right)_{2} \mathrm{SO}_{4}$ conditions in soil. For example, we frequently detected Nitrocosmicus and Nitrososphaeraceae (archaea) [53] and A. insolitus and A. denitrificans, (bacteria) [54], which are known to be nitrophilic organisms.

\section{Positive effects of bio-based and biodegradable plastic on soil systems}

Bio-based and biodegradable plastics may introduce some beneficial microbes to the soil system and facilitate their enrichment [24]. In this study, beneficial microbes were enriched in PBSA and/or soil. These beneficial microbes, which included $\mathrm{N}$-fixing bacteria, plant growth-promoting microbes, and biological control agents, can potentially improve plant growth and production [55]. To increase the richness of these beneficial soil microbes, plant species need to be considered. For example, C. globosum can function as either a biological control or a plant pathogenic fungus depending on the plant species with which it is interacting. A previous report showed that C. globosum causes leaf spot disease on potato [56] and pomegranate [57, 58]. Conversely, C. globosum has exhibited biocontrol potential against Colletotrichum, Fusarium, Phytophthora, Pyricularia, Rhizoctonia, and Sclerotium pathogens [59] by suppressing the growth of these fungi through competition for substrates and nutrients, mycoparasitism, antibiosis, or a combination of various mechanisms [60, 61]. The efficacy of C. globosum as a biocontrol agent has also been demonstrated for the control root rot disease in citrus, black pepper, strawberry, damping-off disease in sugar beet as well as late blight disease in potatoes [62, 63].

\section{Negative effects of bio-based and biodegradable plastics on soil systems}

Our study is the first to list the microbes associated with PBSA using in-depth analyses of the fungal, bacterial, and archaeal community compositions at a high resolution. In this study, we detected opportunistic human pathogens in PBSA-soil system. However, these opportunistic human pathogens have also been identified across different environmental samples. Adding PBSA together 
with fertilisation by $\left(\mathrm{NH}_{4}\right)_{2} \mathrm{SO}_{4}$ can increase the abundances of a very important animal and human pathogen, B. melitensis [64]. Some opportunistic human pathogens were enriched in PS-treated PBSA samples, although it was not detected in either the initial or control (Control S and Control SN) soils. These pathogens may also present in the initial and control soils but occurred at extremely low abundances, so that they cannot be detected by using Illumina Miseq sequencing as this technique has a certain detection limit ( $\sim 10$ cells $/ \mathrm{ml})$ [65].

Some plant pathogens were detected or enriched on PBSA and in soil such as I. macrodidyma. F. solani, a plant pathogen with a broad host range, was highly enriched on PBSA under PSN treatment [66], indicating that this fungus was proliferating and metabolically active. Compared with decomposing wheat straw (frequently used as natural mulch [67]) in the field where our initial soil was collected, PBSA (under both PS and PSN treatments) harboured lower number of fungal plant pathogens [68]. Although some crop production studies $[69,70]$ reported stable yield and no disease increases after multiple years of biodegradable mulch application, our results revealed a potential interaction between PBSA and nitrogen fertilisation promoting some important plant pathogens, especially $F$. solani. However, the possibility of disease outbreak may highly depend on plant species, level of $\mathrm{N}$ fertilisation, mulching film waste management, and any other ecosystem properties related to plant-pathogen interaction. To be at the safe side, we suggest to remove PBSA mulching film after use to avoid the accumulation of their residues in soil. Future research should focus on the effects of different forms (manure and synthetic $\mathrm{N}$ fertilisers) and application rates of $\mathrm{N}$ fertilisers on animal, human and plant pathogens, interaction of microbes in the PBSA-soil system and the introduction of beneficial microbes to control plant pathogenic fungi.

\section{Limitations and implications}

Our study clearly illustrates the changes of soil microbial community composition and reduction of their richness due to the high load of PBSA addition and its interaction with $\left(\mathrm{NH}_{4}\right)_{2} \mathrm{SO}_{4}$ fertilisation. Such responses occurred over a relatively short period of 90 days under controlled temperature and moisture conditions in the laboratory. Under real field conditions, soil microbial communities change in response to amendment addition and management (e.g. cover crop, tillage, manure addition, etc.), dominant plant species, and by seasonal effects (e.g. temperature and precipitation fluctuations in winter, spring, summer, and fall) [71, 72], which were beyond the scope of our study. As we used the simplified soil systems addressing the two main factors (PBSA addition and inorganic nitrogen fertilisation), our results may not cover other complex interactions, especially those from plants, seasonal changes, and land use occurring in real ecosystems. Soil moisture, temperature and agricultural practices alter significantly during different seasons [71, 72]. While the disturbances to soil systems as well as the extreme weather conditions (drought, freezing, flooding) can negatively impact soil microbial communities, such negative effects can be strongly reduced with increasing plant diversity [73]. These mentioned factors should be considered in future studies, although mechanistic interpretations are difficult in real ecosystems. Another limitation of our study is the high dose of PBSA addition (6\% PBSA-soil $(w / w))$. This is higher than the dose that normally used for evaluating the effect of plastics in soils (1\%), and the typical dose of the biodegradable plastics mulching film in a normal single use $(\sim 0.0063 \%)$ [74, 75]. Although, there is a possibility that the bio-based and biodegradable mulching films can be highly accumulated in agricultural soils after many years of applications, especially in dry and cold areas where the degradation rate under field conditions is slow [23], the amount may not reach $6 \%$. Such high load of plastic film can be found in land-fill where the percentage reaches $6.5 \%(\mathrm{w} / \mathrm{w})$ [76]. Overall, our results should be interpreted with caution. Our study rather provides information on diverse soil microbial communities associated with PBSA degradation and how they respond to $\left(\mathrm{NH}_{4}\right)_{2} \mathrm{SO}_{4}$ fertilisation. We clearly demonstrated that $\left(\mathrm{NH}_{4}\right)_{2} \mathrm{SO}_{4}$ fertilisation significantly increased the degradation rate of PBSA film which may have an implication for its waste management.

\section{Conclusions}

For the first time, the effects of a bio-based and biodegradable plastic, PBSA, on the soil microbiome have been investigated using high-resolution molecular technique. In contrast to previous reports, we conclude that PBSA significantly affects the soil microbiome; however, different microbial kingdoms have different responses to the presence of PBSA. We show that adding PBSA to soil facilitated the growth of a fungal minority, thereby reducing the fungal richness and strongly changing both bacterial and fungal community composition. The combined amendment additions of PBSA and $\mathrm{N}$ fertilisation [in the form of $\left(\mathrm{NH}_{4}\right)_{2} \mathrm{SO}_{4}$ ] on the soil microbiome are much greater than the effects of PBSA alone owing to a strong decrease in soil $\mathrm{pH}$ and a shift in the soil microbiome towards nitrophilic microbes. We only detected some opportunistic human pathogens, except when $\left(\mathrm{NH}_{4}\right)_{2} \mathrm{SO}_{4}$ fertilisation was used in combination with PBSA, which increased the sequence read abundances of the animal and human pathogen B. melitensis. Plant pathogenic fungi were also detected and enriched in PBSA films as well as in the surrounding soils. Adding PBSA 
and $\mathrm{N}$ fertilisation can either reduce the sequence read abundances of some plant pathogens to almost zero or increase the abundance of specific pathogens, especially the economically important pathogen F. solani. Apart from plant pathogens, we also detected many potential microbial control agents and plant growth-promoting microorganisms owing to PBSA addition. Future studies should focus on evaluating the effects of bio-based and biodegradable plastics on the soil microbiome, plantmicrobe interactions, and soil feedbacks under various field conditions.

\section{Abbreviations}

ASVs: Amplicon sequence variants; C:N ratio: Carbon:nitrogen ratio; PBAT: Polybutylene adipate terephthalate; PBS: Polybutylene succinate; PBSA: Polybutylene succinate-co-adipate; PHA: Polyhydroxyalkanoate; PLA: Polylactic acid.

\section{Supplementary Information}

The online version contains supplementary material available at https://doi. org/10.1186/s12302-021-00528-5.

\section{Additional file 1: Appendix 1. PBSA chemical and physical proper-} ties. Figure S1. Rarefaction curves of archaea (a), bacteria (b), and fungi (c). Figure S2. Links between soil pH and microbial richness: a) Soil pH values of initial soil, initial-N soil, control S, control SN, and soils in PS, and PSN treatment on 90 days. Correlations between soil $\mathrm{pH}$ and richness of archaea (b), bacteria (c) and fungi (d). Figure S3. Factors explain variations in microbial community composition: percent explainable variations of archaeal (a), bacterial (b), and fungal (c) communities explained by PBSA addition, $\mathrm{N}$ fertilization, soil $\mathrm{pH}$, and combinations of these factors. Total variations of archaeal, bacterial, and fungal communities explained by PBSA addition, $\mathrm{N}$ fertilization, soil $\mathrm{pH}$, and combinations of these factors are 13, 23 and 28\%, respectively. Table S4. Comparisons between microbial community compositions of (i) PBSA and soil counterparts and (ii) soils of different treatments and (iii) control soils (Control S and Control SN) and PBSA (PS and PSN treatments) using analysis of similarities (ANOSIM) and non-parametric multivariate analysis of variance (NPMANOVA).

Additional file 2: Table S1. Information on relative abundance (\%) of archaeal ASVs detected in poly(butylene succinate-co-adipate) (PBSA) and soils of all treatments. Please see in another excel file. Table S2. Information on relative abundance (\%) of bacterial ASVs detected in poly(butylene succinate-co-adipate) (PBSA) and soils of all treatments. Please see in another excel file. Table S3. Information on relative abundance (\%) of fungal ASVs detected in poly(butylene succinate-co-adipate) (PBSA) and soils of all treatments. Please see in another excel file.

\section{Acknowledgements}

The community composition data have been computed at the High-Performance Computing (HPC) Cluster EVE, a joint effort of both the Helmholtz Centre for Environmental Research-UFZ and the German Centre for Integrative Biodiversity Research (iDiv) Halle-Jena-Leipzig. The authors thank Anna Heintz-Buschart (Metagenomics Support Unit, German Centre for Integrative Biodiversity Research (iDiv) Halle-Jena-Leipzig) for bioinformatics support and helpful discussions. We thank the Helmholtz Association, the Federal Ministry of Education and Research, the State Ministry of Science and Economy of Saxony-Anhalt, and the State Ministry for Higher Education, Research and the Arts Saxony for funding the Global Change Experimental Facility (GCEF) project. We also thank the staff of the Bad Lauchstädt Experimental Research Station (especially Ines Merbach and Konrad Kirsch) for their work in maintaining the plots and infrastructures of the GCEF, and Dr. Stefan Klotz, Dr. Martin Schädler, Dr. Harald Auge, and Dr. Thomas Reitz for their roles in setting up the GCEF. We acknowledge a support of the RUDN University Strategic Academic Leadership Program. We thank The Islamic Development Bank for the funding of Vusal Guliyev. We also would like to acknowledge the DAAD for providing the opportunity for Maria Udovenko to participate in the project.

\section{Authors' contributions}

WP, EB and BT conceived and designed the study. BT, WP, VG, MU and SW led the laboratory experimental setup. BT, WP, EB, MU and VG collected the samples and metadata. WP, EB and FB contributed reagents and laboratory equipment. BT, WP, and SW led the DNA analysis. SW led bioinformatics. BT, WP and $\mathrm{KJ}$ led the microbial taxonomy and data analyses. BT, KJ and WP wrote the manuscript. BG and WP supervised BT. MN, BG, ASL, EGA, EB and FB reviewed and gave comments and suggestions for manuscript. All authors have read and approved the final manuscript.

\section{Funding}

Open Access funding enabled and organized by Projekt DEAL. This work has been partially funded by the internal research budget to Department of Soil Ecology, UFZ-Helmholtz Centre for Environmental Research.

\section{Availability of data and materials}

The Illumina sequencing of prokaryotic and fungal datasets are deposited in The National Center for Biotechnology Information (NCBI) database under BioProject ID: PRJNA702448 (http://www.ncbi.nlm.nih.gov/bioproject/702448). Microbial taxonomic and relative abundance information is provided in Additional file 2 Table S1, S2 and S3.

\section{Declarations}

\section{Ethics approval and consent to participate}

Not applicable.

\section{Consent for publication \\ Not applicable.}

\section{Competing interest}

The authors declare that they have no competing interests. The authors declare that they have no known competing financial interests or personal relationships that could have appeared to influence the work reported in this paper.

\section{Author details}

${ }^{1}$ Department of Soil Ecology, UFZ-Helmholtz Centre for Environmental Research, Theodor-Lieser-Str. 4, 06120 Halle (Saale), Germany. ${ }^{2}$ Department of Biomedical Science and Biomedical Engineering, Faculty of Medicine, Prince of Songkla University, Songkhla 90110, Thailand. ${ }^{3}$ Department of Biology, Leipzig University, Leipzig, Germany. ${ }^{4}$ Botany Department, Faculty of Science, Suez Canal University, Ismailia 41522, Egypt. ${ }^{5}$ Institute of Soil Science and Agrochemistry of Azerbaijan National Academy of Sciences, M.Rahim, AZ1073, Baku, Azerbaijan. ${ }^{6}$ Biogeochemical Processes Department, Max Planck Institute for Biogeochemistry, Hans-Knöll-Str. 10, 07745 Jena, Germany. ${ }^{7}$ Soil Biogeochemistry, Martin Luther University Halle-Wittenberg, Von-Seckendorff-Platz 3, 06120 Halle (Saale), Germany. ${ }^{8}$ Institute of Bioanalysis, Coburg University of Applied Sciences and Arts, Coburg, Germany. ${ }^{9}$ German Centre for Integrative Biodiversity Research (iDiv) Halle-Jena-Leipzig, Deutscher Platz 5e, 04103 Leipzig, Germany. ${ }^{10}$ Agro-Technological Institute, RUDN University, Miklukho-Maklaya 6, Moscow, 117198, Russia.

Received: 2 March 2021 Accepted: 13 July 2021

Published online: 06 September 2021

\section{References}

1. Emadian SM, Onay TT, Demirel B (2017) Biodegradation of bioplastics in natural environments. Waste Manage 59:526-536. https://doi.org/10. 1016/j.wasman.2016.10.006

2. LiY, Sarkanen S (2003) Biodegradable kraft lignin-based thermoplastics. In: Chiellini E, Solaro R (eds) Biodegradable polymers and plastics. Springer, Boston, pp 121-139

3. Rahman MH, Bhoi PR (2021) An overview of non-biodegradable bioplastics. J Clean Prod 294:126218. https://doi.org/10.1016/j.jclepro.2021. 126218 
4. Haider TP, Völker C, Kramm J et al (2019) Plastics of the future? The impact of biodegradable polymers on the environment and on society. Angew Chem Int Ed 58:50-62. https://doi.org/10.1002/anie.201805766

5. Brizga J, Hubacek K, Feng K (2020) The unintended side effects of bioplastics: carbon, land, and water footprints. One Earth 3:45-53. https://doi. org/10.1016/j.oneear.2020.06.016

6. DeVetter L, Liu H, Miles C, Ghimire S (2020) Soil-biodegradable mulches: workshop-Deterioration, degradation and tillage of soil-biodegradable mulch. https://s3.wp.wsu.edu/uploads/sites/2181/2020/11/6.-Deteriorat ion-and-degradation.pdf. Accessed 9 July 2021

7. Ciriminna R, Pagliaro M (2019) Biodegradable and compostable plastics: a critical perspective on the dawn of their global adoption. ChemistryOpen 9:8-13. https://doi.org/10.1002/open.201900272

8. Puchalski M, Szparaga G, Biela T et al (2018) Molecular and supramolecular changes in polybutylene succinate (PBS) and polybutylene succinate adipate (PBSA) copolymer during degradation in various environmental conditions. Polymers 10:251. https://doi.org/10.3390/polym10030251

9. Gigli M, Negroni A, Soccio M et al (2012) Influence of chemical and architectural modifications on the enzymatic hydrolysis of poly(butylene succinate). Green Chem 14:2885-2893. https://doi.org/10.1039/C2GC3 5876」

10. Mizuno S, Maeda T, Kanemura C, Hotta A (2015) Biodegradability, reprocessability, and mechanical properties of polybutylene succinate (PBS) photografted by hydrophilic or hydrophobic membranes. Polym Degrad Stab 117:58-65. https://doi.org/10.1016/j.polymdegradstab.2015.03.015

11. Babu RP, O'Connor K, Seeram R (2013) Current progress on bio-based polymers and their future trends. Prog Biomater 2:8. https://doi.org/10. 1186/2194-0517-2-8

12. Bandopadhyay S, Martin-Closas L, Pelacho AM, DeBruyn JM (2018) Biodegradable plastic mulch films: impacts on soil microbial communities and ecosystem functions. Front Microbiol. https://doi.org/10.3389/fmicb. 2018.00819

13. Brunner CT, Baran ET, Pinho ED et al (2011) Performance of biodegradable microcapsules of poly(butylene succinate), poly(butylene succinate-co-adipate) and poly(butylene terephthalate-co-adipate) as drug encapsulation systems. Colloids Surf B 84:498-507. https://doi.org/ 10.1016/j.colsurfb.2011.02.005

14. Serrano-Ruiz H, Martin-Closas L, Pelacho AM (2021) Biodegradable plastic mulches: impact on the agricultural biotic environment. Sci Total Environ 750:141228. https://doi.org/10.1016/j.scitotenv.2020.141228

15. Barron A, Sparks TD (2020) Commercial Marine-Degradable Polymers for Flexible Packaging. iScience. 23:101353. https://doi.org/10.1016/j.isci. 2020.101353

16. Ritchie H, Roser M (2018) Plastic Pollution. Our World in Data. https:// ourworldindata.org/plastic-pollution. Accessed 9 July 2021

17. Kyrikou I, Briassoulis D (2007) Biodegradation of agricultural plastic films: a critical review. J Polym Environ 15:125-150. https://doi.org/10.1007/ s10924-007-0053-8

18. Koitabashi M, Noguchi MT, Sameshima-Yamashita Y et al (2012) Degradation of biodegradable plastic mulch films in soil environment by phylloplane fungi isolated from gramineous plants. AMB Express 2:40. https:// doi.org/10.1186/2191-0855-2-40

19. van Emmerik T, Schwarz A (2020) Plastic debris in rivers. WIREs. Water 7:e1398. https://doi.org/10.1002/wat2.1398

20. Yu Y, Flury M (2021) Current understanding of subsurface transport of micro- and nanoplastics in soil. Vadose Zone J 20:e20108. https://doi.org/ 10.1002/vzj2.20108

21. Shah AA, Eguchi T, Mayumi D et al (2013) Degradation of aliphatic and aliphatic-aromatic co-polyesters by depolymerases from Roseateles depolymerans strain TB-87 and analysis of degradation products by LC-MS. Polym Degrad Stab 98:2722-2729. https://doi.org/10.1016/j. polymdegradstab.2013.10.003

22. Lee JW, Han M-S, Choi S et al (2011) 3.15-Organic acids: succinic and malic acids. In: Moo-Young M (ed) Comprehensive biotechnology, 2nd edn. Academic Press, Burlington, pp 149-161

23. Hoshino A, Sawada H, Yokota M et al (2001) Influence of weather conditions and soil properties on degradation of biodegradable plastics in soil. Soil Sci Plant Nutr 47:35-43. https://doi.org/10.1080/00380768.2001. 10408366
24. Gan Z, Zhang H (2019) PMBD: a comprehensive plastics microbial biodegradation database. Database. https://doi.org/10.1093/database/ baz119

25. Moore-Kucera J, Cox SB, Peyron M et al (2014) Native soil fungi associated with compostable plastics in three contrasting agricultural settings. Appl Microbiol Biotechnol 98:6467-6485. https://doi.org/10.1007/ s00253-014-5711-x

26. Adhikari D, Mukai M, Kubota K et al (2016) Degradation of bioplastics in soil and their degradation effects on environmental microorganisms. J Agric Chem Environ 5:23-34. https://doi.org/10.4236/jacen.2016.51003

27. Crawford SE, Hartung T, Hollert $\mathrm{H}$ et al (2017) Green toxicology: a strategy for sustainable chemical and material development. Environ Sci Eur 29:16. https://doi.org/10.1186/s12302-017-0115-z

28. Francioli D, Schulz E, Lentendu G et al (2016) Mineral vs. organic amendments: microbial community structure, activity and abundance of agriculturally relevant microbes are driven by long-term fertilization strategies. Front Microbiol. https://doi.org/10.3389/fmicb.2016.01446

29. Schädler M, Buscot F, Klotz S et al (2019) Investigating the consequences of climate change under different land-use regimes: a novel experimental infrastructure. Ecosphere 10:e02635. https://doi.org/10.1002/ecs2.2635

30. Belete F, Dechassa N, Molla A, Tana T (2018) Effect of nitrogen fertilizer rates on grain yield and nitrogen uptake and use efficiency of bread wheat (Triticum aestivum L.) varieties on the Vertisols of central highlands of Ethiopia. Agric Food Sec 7:78. https://doi.org/10.1186/ s40066-018-0231-Z

31. Zebarth BJ, Bowen PA, Toivonen PMA (1995) Influence of nitrogen fertilization on broccoli yield, nitrogen accumulation and apparent fertilizernitrogen recovery. Can J Plant Sci 75:717-725. https://doi.org/10.4141/ c.jps95-122

32. Cosgrove L, McGeechan PL, Robson GD, Handley PS (2007) Fungal communities associated with degradation of polyester polyurethane in soil. Appl Environ Microbiol 73:5817-5824. https://doi.org/10.1128/AEM. 01083-07

33. Caporaso JG, Lauber CL, Walters WA et al (2011) Global patterns of $16 \mathrm{~S}$ rRNA diversity at a depth of millions of sequences per sample. Proc Natl Acad Sci USA 108:4516-4522. https://doi.org/10.1073/pnas.1000080107

34. Ihrmark K, Bödeker ITM, Cruz-Martinez K et al (2012) New primers to amplify the fungal ITS2 region-evaluation by 454-sequencing of artificial and natural communities. FEMS Microbiol Ecol 82:666-677. https:// doi.org/10.1111/j.1574-6941.2012.01437.x

35. White TJ, Bruns TD, Lee S, Taylor J (1990) Amplification and direct sequencing of fungal ribosomal RNA genes for phylogenetics. In: Innis MA, Gelfand DH, Sninsky JJ, White TJ (eds) PCR protocols: a guide to methods and applications. Academic Press, San Diego, pp 315-322

36. Martin M (2011) Cutadapt removes adapter sequences from highthroughput sequencing reads. EMBnet J 17:10-12. https://doi.org/10. 14806/ej.17.1.200

37. Callahan BJ, McMurdie PJ, Rosen MJ et al (2016) DADA2: High-resolution sample inference from Illumina amplicon data. Nat Methods 13:581-583. https://doi.org/10.1038/nmeth.3869

38. Weißbecker C, Schnabel B, Heintz-Buschart A (2020) Dadasnake, a Snakemake implementation of DADA2 to process amplicon sequencing data for microbial ecology. Gigascience. https://doi.org/10.1093/gigascience/ giaa135

39. Köljalg U, Nilsson RH, Abarenkov K et al (2013) Towards a unified paradigm for sequence-based identification of fungi. Mol Ecol 22:5271-5277. https://doi.org/10.1111/mec.12481

40. Callahan BJ, McMurdie PJ, Holmes SP (2017) Exact sequence variants should replace operational taxonomic units in marker-gene data analysis. ISME J 11:2639-2643. https://doi.org/10.1038/ismej.2017.119

41. Nilsson RH, Larsson K-H, Taylor AFS et al (2019) The UNITE database for molecular identification of fungi: handling dark taxa and parallel taxonomic classifications. Nucleic Acids Res 47:D259-D264. https://doi.org/ 10.1093/nar/gky1022

42. Nguyen NH, Song Z, Bates ST et al (2016) FUNGuild: an open annotation tool for parsing fungal community datasets by ecological guild. Fungal Ecol 20:241-248. https://doi.org/10.1016/j.funeco.2015.06.006

43. Sansupa C, Wahdan SFM, Hossen S et al (2021) Can we use functional annotation of prokaryotic taxa (FAPROTAX) to assign the ecological functions of soil bacteria? Appl Sci 11:688. https://doi.org/10.3390/app11 020688 
44. Amend AS, Seifert KA, Bruns TD (2010) Quantifying microbial communities with 454 pyrosequencing: does read abundance count? Mol Ecol 19:5555-5565. https://doi.org/10.1111/j.1365-294X.2010.04898.x

45. Oksanen J, Blanche FG, Friendly M, et al (2016) Vegan: Community Ecology Package. R-package version 2.4-0

46. Akutsu-Shigeno Y, Teeraphatpornchai T, Teamtisong K (2003) Cloning and sequencing of a poly(dl-lactic acid) depolymerase gene from Paenibacillus amylolyticus strain TB-13 and its functional expression in Escherichia coli. Appl Environ Microbiol 69(5):2498-2504. https://doi.org/10.1128/ AEM.69.5.2498-2504.2003

47. Abe M, Kobayashi K, Honma N, Nakasaki K (2010) Microbial degradation of poly(butylene succinate) by Fusarium solani in soil environments. Polym Degrad Stab 95:138-143. https://doi.org/10.1016/j.polymdegra dstab.2009.11.042

48. Maia MMD, Heasley A, Camargo de Morais MM et al (2001) Effect of culture conditions on lipase production by Fusarium solani in batch fermentation. Biores Technol 76:23-27. https://doi.org/10.1016/S09608524(00)00079-1

49. Purahong W, Wahdan SFM, Heinz D, et al (2021) Back to the future: decomposability of a bio-based and biodegradable plastic in field soil environments and its microbiome under ambient and future climates. Environmental Science and Technology. (in press)

50. Song Y, Laureijssen-van de Sande WWJ, Moreno LF et al (2017) Comparative ecology of capsular Exophiala species causing disseminated infection in humans. Front Microbiol. https://doi.org/10.3389/fmicb.2017.02514

51. Fageria NK, dos Santos AB, Moraes MF (2010) Influence of urea and ammonium sulfate on soil acidity indices in lowland rice production. Commun Soil Sci Plant Anal 41:1565-1575. https://doi.org/10.1080/00103 624.2010 .485237

52. Zhang X, Liu W, Zhang G et al (2015) Mechanisms of soil acidification reducing bacterial diversity. Soil Biol Biochem 81:275-281. https://doi. org/10.1016/j.soilbio.2014.11.004

53. Lehtovirta-Morley LE, Ross J, Hink L et al (2016) Isolation of 'Candidatus Nitrosocosmicus franklandus', a novel ureolytic soil archaeal ammonia oxidiser with tolerance to high ammonia concentration. FEMS Microbiol Ecol. https://doi.org/10.1093/femsec/fiw057

54. Su J, Liang D, Lian T (2018) Comparison of denitrification performance by bacterium Achromobacter sp. A14 under different electron donor conditions. Chem Eng J 333:320-326. https://doi.org/10.1016/j.cej.2017.09.129

55. Meena M, Swapnil P, Zehra A et al (2017) Beneficial microbes for disease suppression and plant growth promotion. In: Singh DP, Singh HB, Prabha $R$ (eds) Plant-microbe interactions in agro-ecological perspectives. Microbial interactions and agro-ecological impacts, vol 2. Springer, Singapore, pp 395-432

56. Seth HK (1970) A Monograph of the genus Chaetomium. Beihefte zur Nova Hedwigia 37:1-133

57. Alam MW, Malik A, Rehman A, et al (2021) First record of Chaetomium globosum causing leaf spot of pomegranate in Pakistan. Plant Disease. https://doi.org/10.1094/PDIS-01-21-0200-PDN

58. Guo J-W, Cheng J-S, Yang L-F et al (2015) First report of a leaf spot disease caused by Chaetomium globosum on pomegranate from Yunnan China. Plant Dis 100:223. https://doi.org/10.1094/PDIS-03-15-0243-PDN

59. Soytong K, Kanokmedhakuf S, Kanokmedhakul S et al (2001) Application of Chaetomium species (Ketomium R) as a new broad spectrum biological fungicide for plant disease control. Fungal Divers 7:1-15

60. Marwah RG, Fatope MO, Deadman ML et al (2007) Musanahol: a new aureonitol-related metabolite from a Chaetomium sp. Tetrahedron 63:8174-8180. https://doi.org/10.1016/j.tet.2007.05.119

61. Zhang H, Yang Q (2007) Expressed sequence tags-based identification of genes in the biocontrol agent Chaetomium cupreum. Appl Microbiol Biotechnol 74:650-658. https://doi.org/10.1007/s00253-006-0701-2

62. Tomilova OG, Shternshis MV (2006) The effect of a preparation from Chaetomium fungi on the growth of phytopathogenic fungi. Appl Biochem Microbiol 42:67-71. https://doi.org/10.1134/S0003683806010108

63. Shanthiyaa V, Saravanakumar D, Rajendran L et al (2013) Use of Chaetomium globosum for biocontrol of potato late blight disease. Crop Prot 52:33-38. https://doi.org/10.1016/j.cropro.2013.05.006

64. Wallach JC, Samartino LE, Efron A, Baldi PC (1997) Human infection by Brucella melitensis: an outbreak attributed to contact with infected goats.
FEMS Immunol Med Microbiol 19:315-321. https://doi.org/10.1111/j. 1574-695X.1997.tb01102.x

65. Brandt J, Albertsen M (2018) Investigation of detection limits and the influence of DNA extraction and primer choice on the observed microbial communities in drinking water samples using $16 \mathrm{~S}$ rRNA gene amplicon sequencing. Front Microbiol. https://doi.org/10.3389/fmicb. 2018.02140

66. Coleman JJ (2016) The Fusarium solani species complex: ubiquitous pathogens of agricultural importance. Mol Plant Pathol 17:146-158. https://doi.org/10.1111/mpp.12289

67. Wang J, Zhang Y, Gong S et al (2018) Effects of straw mulching on microclimate characteristics and evapotranspiration of drip-irrigated winter wheat in North China Plain. Int J Agric Biol Eng 11:122-131. https://doi. org/10.25165/ijabe.v11i2.3192

68. Wahdan SFM, Hossen S, Tanunchai B et al (2020) Future climate significantly alters fungal plant pathogen dynamics during the early phase of wheat litter decomposition. Microorganisms 8:908. https://doi.org/10. 3390/microorganisms8060908

69. Tofanelli MBD, Wortman SE (2020) Benchmarking the agronomic performance of biodegradable mulches against polyethylene mulch film: a meta-analysis. Agronomy 10:1618. https://doi.org/10.3390/agronomy10 101618

70. Moore JC, Wszelaki AL (2019) The use of biodegradable mulches in pepper production in the Southeastern United States. HortScience 54:1031-1038. https://doi.org/10.21273/HORTSCl13942-19

71. Hartman K, van der Heijden MGA, Wittwer RA et al (2018) Cropping practices manipulate abundance patterns of root and soil microbiome members paving the way to smart farming. Microbiome 6:14. https://doi. org/10.1186/s40168-017-0389-9

72. Chernov TI, Zhelezova AD (2020) The dynamics of soil microbial communities on different timescales: a review. Eurasian Soil Sc 53:643-652. https://doi.org/10.1134/S106422932005004X

73. Bennett JA, Koch AM, Forsythe J et al (2020) Resistance of soil biota and plant growth to disturbance increases with plant diversity. Ecol Lett 23:119-128. https://doi.org/10.1111/ele.13408

74. Qi Y, Yang X, Pelaez AM et al (2018) Macro- and micro- plastics in soilplant system: effects of plastic mulch film residues on wheat (Triticum aestivum) growth. Sci Total Environ 645:1048-1056. https://doi.org/10. 1016/j.scitotenv.2018.07.229

75. Sforzini S, Oliveri L, Chinaglia S, Viarengo A (2016) Application of biotests for the determination of soil ecotoxicity after exposure to biodegradable plastics. Front Environ Sci. https://doi.org/10.3389/fenvs.2016.00068

76. Xochitl Q-P, María del Consuelo H-B, María del Consuelo M-S et al (2021) Degradation of plastics in simulated landfill conditions. Polymers 13:1014. https://doi.org/10.3390/polym13071014

\section{Publisher's Note}

Springer Nature remains neutral with regard to jurisdictional claims in published maps and institutional affiliations. 